\title{
Formação dos professores para o atendimento educacional especializado em contexto indígena
}

\author{
João Henrique da Silva \\ Universidade Federal de São Carlos \\ Marilda Moraes Garcia Bruno \\ Universidade Federal da Grande Dourados
}

\section{Resumo}

Este estudo analisa a formação de professores para o Atendimento Educacional Especializado (AEE) na interface com a Educação Indígena. Participaram do estudo 4 professores do AEE em escolas indígenas de Dourados-MS e fundamentouse nos Estudos Culturais e na pesquisa colaborativa fazendo uso de diário de campo, entrevista semiestruturada e coletiva. Os resultados evidenciaram: necessidade de formação inicial/continuada para professores do AEE adequadas às especificidades das escolas indígenas; revisão da política de formação dos professores para a Educação Especial em contextos socioculturais diferenciados; e a emergência de (re)significação do AEE numa perspectiva intercultural.

Palavras-chave: Formação de Professores. Atendimento Educacional Especializado. Educação Indígena. 


\section{Teachers' formation for specialized education service in indigenous context}

This paper analyses the teachers' formation for Specialized Education Service (SES) at the interface with Indigenous Education. The study involved 4 SES teachers from indigenous schools of Dourados-MS. It was based on Cultural Studies and collaborative research, using field diary and semi-structured and collective interviews. The results highlight: the need for initial/continuing formation for SES teachers, appropriated to the specific characteristics of indigenous schools; a review of teacher formation policy for Special Education in different socio-cultural contexts; and the emergence of (re)signification of SES from an intercultural perspective.

Keywords: Teacher formation. Specialized Education Service. Indigenous Education.

\section{Formación de los profesores para el atendimiento educacional especializado en el contexto indio}

Este artículo analiza la formación de los profesores para el Atendimiento Educacional Especializado (AEE) en la interface con la Educación Indígena. Participaran del estudio 4 profesores del AEE en las escuelas indígenas de Dourados-MS. Se fundamentó en los estudios culturales y en la investigación colaborativa haciendo uso de diario de campo y entrevistas semi estructuradas e colectiva. Los resultados mostraron: la necesidad de la formación inicial/continua para los profesores de la AEE adecuadas a las características específicas de las escuelas indígenas; una revisión de la política de formación de los profesores para la Educación Especial en los diferentes contextos socio-culturales; y la emergencia de la (re)significación del AEE en una perspectiva intercultural.

Palabras clave: Formación de Profesores. Atendimiento Educacional Especializado. Educación Indígena. 


\section{Introdução}

O presente texto versa sobre a formação inicial e continuada dos professores do atendimento educacional especializado (AEE) em escolas da Terra Indígena de Dourados (TID). Esta temática envolve duas modalidades: educação especial e educação escolar indígena. Ambas as modalidades constituem campos de conhecimentos distintos, mas possíveis de serem conciliados e traduzidos culturalmente para a implementação de uma nova configuração no cenário político de formação docente.

Como pondera Laclau (2011), a política para as diferenças não é um processo tranquilo, envolve tensões, disputas de poder e requer negociações. $\mathrm{Na}$ construção e efetivação da política de formação de professores para a educação especial, em contextos diferenciados, as identidades dos professores entram em conflito, tanto com identidades universalistas quanto com particulares, em relação ao contexto e aos valores da escola diferenciada indígena.

Nesta pesquisa, constatou-se que a política de formação dos professores indígenas tem incorporado às diretrizes de formação da educação especial, elaboradas para as escolas não indígenas. Discute-se a ausência de diálogo em relação aos princípios, crenças e fundamentos da educação indígena. Assim, este texto aborda aspectos teóricos e metodológicos do estudo, apresentando o perfil e a formação dos professores indígenas, bem como suas percepções sobre as tarefas que desempenham. Os dados apresentados instigam a revisão das políticas de formação docente e condições de trabalho no AEE.

\section{O Delineamento teórico-metodológico da pesquisa}

A presente pesquisa faz parte de um macroprojeto apoiado pela CAPES, denominado "Mapeamento de deficiências na população indígena na região da Grande Dourados-MS" que estudou os impactos e as possíveis implicações para a inclusão educacional dessa população. Este subprojeto foi desenvolvido em conjunto com os professores que atuam no AEE, nas escolas indígenas de DouradosMS, por meio de um programa de formação continuada para investigar as ações pedagógicas nas salas de recursos multifuncionais (SRMs), bem como analisar os impasses, obstáculos e desafios para a inclusão escolar.

O cenário do estudo constituiu-se das 4 salas de recursos existentes nas escolas indígenas de Dourados, localizadas nas aldeias Jaguapiru e Bororó. Participaram da pesquisa 5 professoras, das quais 3 indígenas que atuam nas salas de recursos dessas escolas, identificados como P1, P2, P3, P4 e P5. Todas as participantes foram 
mulheres que tinham contato entre si, uma vez que frequentavam os cursos de formação continuada oferecidos pela Secretaria Municipal de Educação (Semed). Cabe acrescentar que 45 professores do ensino regular que ensinam nas escolas indígenas participaram de alguns encontros do ciclo de formação.

Para analisar a formação dos professores para o AEE no locus das escolas indígenas, o estudo fundamentou-se na antropologia, com ênfase nos Estudos Culturais. A educação especial no contexto da educação diferenciada indígena constitui-se num novo campo de estudos assentado em políticas culturais que atendem às demandas dos movimentos sociais tradicionalmente excluídos das políticas educacionais. Os principais expoentes são: Bhabha (1998), Bauman (2005), Hall (2003; 2006), García Canclini (2008), Geertz (2001; 2008), Laclau (2011), Santos (2004; 2009) e Walsh (2009).

Os conceitos essenciais foram: cultura, entre-lugar, hibridação intercultural, identidades e tradução cultural. Essas premissas permitiram compreender que o ser humano é tecido por relações sociais, através das quais constituem suas identidades. Ele transita entre diferentes fronteiras sociais e culturais, o que instiga a traduzir-se culturalmente para operar nos interstícios sociais.

Para Geertz (2001, p. 215), as culturas são "[...] estruturas de sentido em que as pessoas vivem e formam suas convicções, suas individualidades e seus estilos de solidariedade" e uma "[...] força ordenadora das questões humanas". Neste conceito essencialmente semiótico, Geertz (2008) pensa que o ser humano é um animal amarrado a teias de significados que ele mesmo teceu. Assim, as culturas são sistemas entrelaçados de signos interpretáveis (símbolos). A cultura refere-se a um contexto em que os acontecimentos sociais, os comportamentos, as instituições ou os processos podem ser descritos de forma inteligível, ou seja, descritos com densidade (Geertz, 2008, p. 24).

Entretanto, Bhabha (1998, p. 19), coloca a cultura na esfera do "além" e na existência humana atual, "[...] marcada por uma tenebrosa sensação de sobrevivência, de viver nas fronteiras do "presente". Hoje, não se fala mais de "classe" ou de "gênero" como categoriais fundantes para compreender o ser humano. Parte-se de uma consciência das posições do sujeito. A reflexão de Bhabha (1998, p. 20) busca compreender os "[...] processos que são produzidos na articulação de diferenças culturais". O termo central é entre-lugares, que apresenta "[...] novos signos de identidades e postos inovadores de colaboração e contestação, no ato de definir a própria ideia de sociedade" (Bhabha, 1998, p. 20).

De acordo com García Canclini (2008), a cultura articula-se com o termo "hibridação intercultural". Para o estudo da educação especial no contexto da educação indígena, torna-se fundamental a posição do pesquisador para analisar as manifestações que emergem dos cruzamentos ou em suas margens, ou seja, perceber a hibridação intercultural. Esta pode ser compreendida entre as duas disciplinas pela "[...] quebra 
e a mescla das coleções organizadas pelos sistemas culturais, a desterritorialização dos processos simbólicos e a expansão dos gêneros impuros" (García Canclini, 2008, p. 286). Neste estudo, conforme orienta García Canclini, a cultura não é um sistema homogêneo, fixo e estável. Ela consiste num entrecruzar dos processos culturais, sociais, políticos e econômicos, este será o fio condutor das análises propostas no presente estudo.

Já na perspectiva de Hall (2003), a cultura se constitui de dispositivos discursivos, simbólicos e representacionais de um povo, sendo que estes dispositivos não são coerentes dentro de um país ou até mesmo no interior de um grupo. Segundo o autor, falar de cultura incita a pensar na interdisciplinaridade na formação do sujeito, uma vez que existem culturas (no plural) e múltiplas identidades do sujeito. Hall ressalta que as identidades são descentradas, deslocadas e fragmentadas. Entretanto, os diferentes elementos da identidade podem ser conjuntamente articulados, mas parcialmente, porque a "estrutura das identidades permanece aberta" (Hall, 2006, p. 17).

De um modo geral, para os Estudos Culturais, as identidades não são "puras" e "autênticas", devido aos processos de hibridação que, por sua vez, são processos de intersecções e transações, levando a uma interculturalidade. Esta é uma condição irrevogável, já que "hoje não existem somente culturas diferentes, mas, também, maneiras desiguais com que os grupos se apropriam de elementos de várias sociedades, combinando-os e transformando-os" (Escosteguy, 2010, p. 185).

Essa linha de reflexão indica falar de identidades no plural para o sujeito contemporâneo, ao mesmo tempo em que exige falar de um ser humano que vivencia a hibridação cultural. Assim, Bhabha reflete que o homem contemporâneo faz a experiência de "viver nas fronteiras". Ele está no "além", no espaço intermediário. Residir no além significa "[...] ser parte de um tempo revisionário, um retorno ao presente para redescrever nossa contemporaneidade cultural; reinscrever nossa comunidade humana, histórica; tocar o futuro em seu lado de cá" (Bhabha, 1998, p. 27, grifos do autor).

Existe assim um aspecto fronteiriço da cultura que leva em consideração a tradução cultural e o entre-lugar como contingente, que inova e interrompe a atuação do presente. Ademais, a configuração atual constitui num "[...] espaço cultural híbrido que surge contingente e disjuntivamente na inscrição de signos da memória cultural e de lugares de atividade política" (Bhabha, 1998, p. 27).

Desse modo, a partir dos ensinamentos de Bhabha (1998), os povos indígenas e as culturas sobrevivem se operarem nos interstícios de uma gama de práticas se conseguirem transitar entre as diferenças sociais e culturais, principalmente, porque vivem num período de maciça diáspora econômica decorrente do capitalismo transnacional e do empobrecimento do terceiro mundo (ou como dizem os discursos oficiais, um país em desenvolvimento). Estes, por sua vez, influenciam as condições 
de deslocamento cultural e de discriminação social, como reflete Bhabha (1998).

Com efeito, a vida humana e a cultura não são as mesmas. Elas não estão engessadas nas estruturas ou formas de culturas "nacionais". Pensá-las hoje requer mirá-las com cuidado e reflexividade, porque elas têm múltiplas identidades, faz a experiência de uma hibridação cultural e estão amarradas às teias de significados, bem como precisam saber viver nos interstícios sociais.

Os conceitos apresentados anunciam que a formação de professores para o $\mathrm{AEE}$, nas escolas indígenas, necessita ter como ponto de partida as culturas e as representações da deficiência da etnia Guarani-Kaiowá, uma vez que a cultura carrega os significados do grupo. Também revela que a situação das crianças com deficiência nas escolas indígenas e a formação desses profissionais encontram-se em espaços intersticiais, nos entre-lugares. A atuação dos professores do AEE requer traduzir culturalmente as diferentes experiências de vida: a hibridação cultural entre esses profissionais incentiva a negociação dos saberes e novas identidades.

Quanto ao delineamento metodológico, trata-se de uma pesquisa colaborativa (Ibiapina, 2008), com observação participante. Foi organizada em duas etapas: a primeira, partiu da revisão bibliográfica, do estudo documental e dos contatos iniciais com as escolas e a comunidade. A segunda etapa, caracterizou-se pela pesquisa de campo, registros dos dados no diário de campo e a entrevista coletiva. O ciclo de formação foi composto por 14 encontros, dos quais os 2 primeiros foram para levantamento de temáticas escolhidas pelas professoras e planejamento dos encontros. Em outros 2 encontros, foram apresentados e discutidos os resultados das 5 pesquisas realizadas sobre o acesso e a escolarização de crianças indígenas com deficiência na região da Grande Dourados. Os demais encontros, num total de 10 , versaram sobre os seguintes temas: aspectos normativos e pedagógicos do $A E E$, princípios da educação escolar indígena e organização do $A E E$, práticas pedagógicas para as crianças com deficiência intelectual, física, auditiva e visual.

Desse modo, esse programa de formação oportunizou um espaço de formação e de reflexão sobre a prática pedagógica das professoras. A proposta foi de repensar o modelo do AEE para as escolas indígenas, à luz dos teóricos e estudiosos da temática da educação especial e educação indígena. Os encontros desse programa também permitiram dialogar com as especificidades da cultura indígena, investigando como aconteceu a formação acadêmica e continuada dessas professoras.

Para a análise dos dados utilizou-se o recurso da triangulação, cujo objetivo foi analisar, comparar e contradizer as informações obtidas pelas diferentes técnicas. Esse recurso também contempla o exame da revisão da literatura e o estudo documental e os múltiplos pontos de vista dos professores. 


\section{Perfil de formação inicial das professoras do atendimento educacional especializado}

A formação de professores indígenas para o AEE pode ser caracterizada na atual política educacional brasileira como marcada por tensões. Até o ano de 2008 , a interface entre as modalidades de educação especial e de educação indígena estava silenciada. Tanto nos documentos normativos da educação indígena, quanto da educação especial não existia previsão de formação inicial ou continuada para os professores que fossem atuar na interface.

A interface em questão apareceu pela primeira vez na Política Nacional da Educação Especial (PNEE). Ela tem por objetivo "[...] assegurar que os recursos, serviços e atendimentos educacionais especializados estejam presentes nos projetos pedagógicos construídos com base nas diferenças socioculturais desses grupos" (Brasil, 2008, p. 22-23). Anteriormente, o Referencial Curricular Nacional para Escolas Indígenas (Rcnei, 1998) e os Referenciais para a Formação de Professores Indígenas (RFPI, 2002) não estabeleciam a interface com a educação especial. Houve uma iniciativa isolada de discutir com os cursistas da Licenciatura Intercultural Indígena "Teko Arandu" ("Viver com Sabedoria"), a partir de 2010 na Universidade Federal da Grande Dourados (UFGD). O curso contempla na disciplina "Fundamentos de Educação" os conteúdos sobre "políticas públicas de educação inclusiva e de educação especial" (140h). Também possui a disciplina de Libras (30h), como oferta obrigatória regulamentada pelo Decreto $\mathrm{n}^{\circ}$. 5.626/2005.

Somente no ano de 2012, o Parecer CNE/CEB n. 13 observou a ausência de formação de professores indígenas para o AEE. Diante desse desafio, o MEC reconhece a necessidade de criar uma política para o atendimento especializado em escolas indígenas (Brasil, 2012a). No entanto, as novas Diretrizes Curriculares Nacionais para a Educação Escolar Indígena na Educação Básica (Res. n. 5/2012b) não possuem diretrizes para a formação desse profissional do $A E E$. Esta resolução não apresenta propostas de uma qualificação profissional capaz de atender às crianças indígenas com deficiência nas suas escolas. Inclusive, o Plano Nacional de Educação (PNE) 2014-2024 não estabelece o provimento de professores especializados que atendam também a esse contexto, apesar de garantir um trabalho pedagógico que respeite a cultura e a identidade do grupo, bem como recomenda a produção e disponibilização de materiais didáticos específicos, entre outros, para os alunos com deficiência (Brasil, 2014).

Dessa maneira, o suporte para a formação do professor indígena fundamenta-se nas orientações normativas da modalidade da educação especial (Brasil, 2008), o que leva as secretarias municipais de educação a contratarem professores a partir das orientações da modalidade geral da educação especial, contrapondo-se aos princípios de autonomia escolar e às características de uma escola indígena 
diferenciada, específica, bi/multilíngue, comunitária e intercultural (Brasil, 1998).

Com efeito, a Res. CNE/CEB $n^{\circ}$. 5/2012 garante o AEE para as escolas indígenas, mas na forma de reprodução do modelo não-indígena. A interface como interculturalidade, está ainda por ser construída.

Nesta pesquisa levantou-se que o perfil e a formação de professores do AEE da TID, em 2013, são diferenciados, o que pode ser observado no Quadro 1:

\section{Quadro 1: PERFIL E FORMAÇÃO DE PROFESSORES}

\begin{tabular}{|c|c|c|c|c|c|c|}
\hline Professor & Etnia & Local & $\begin{array}{l}\text { Formação } \\
\text { Inicial }\end{array}$ & $\begin{array}{l}\text { Curso de Pós- } \\
\text { Graduação }\end{array}$ & $\begin{array}{l}\text { Experiência na } \\
\text { sala comum } \\
\text { com crianças } \\
\text { em situação de } \\
\text { deficiência }\end{array}$ & $\begin{array}{l}\text { Experiência } \\
\text { na sala de } \\
\text { recursos }\end{array}$ \\
\hline P1 & Terena & $\mathrm{E} 1$ & Pedagogia. & $\begin{array}{l}\text { Especialização em: } \\
\text { Libras - Docência } \\
\text { e Interpretação; } \\
\text { Atendimento } \\
\text { Educacional } \\
\text { Especializado } \\
\text { (UFCE/MEC); } \\
\text { Educação especial. }\end{array}$ & 4 anos & $\begin{array}{l}3 \text { anos } \\
\text { ( } 4^{\circ} \text { ano de } \\
\text { exercício) }\end{array}$ \\
\hline P2 & $\begin{array}{l}\text { Guarani- } \\
\text { Kaiowá }\end{array}$ & E2 & $\begin{array}{l}\text { Normal Médio } \\
\text { (Magistério); } \\
\text { Fisioterapia; } \\
\text { Licenciatura } \\
\text { em Educação } \\
\text { Física. }\end{array}$ & $\begin{array}{l}\text { Especialização em: } \\
\text { Metodologia do } \\
\text { Ensino Superior; } \\
\text { Docência e } \\
\text { Interpretação em } \\
\text { Libras; } \\
\text { Educação Física } \\
\text { Escolar. }\end{array}$ & 5 anos & $\begin{array}{l}2 \text { anos } \\
\text { ( } 2^{\circ} \text { ano de } \\
\text { exercício })\end{array}$ \\
\hline P3 & $\begin{array}{l}\text { Não- } \\
\text { indígena }\end{array}$ & E3 & $\begin{array}{l}\text { Normal } \\
\text { Superior. }\end{array}$ & $\begin{array}{l}\text { Especialização em } \\
\text { Educação Inclusiva }\end{array}$ & +20 anos & $\begin{array}{l}2 \text { anos } \\
\text { ( } 3^{\circ} \text { ano de } \\
\text { exercício) }\end{array}$ \\
\hline P4 & $\begin{array}{l}\text { Não- } \\
\text { indígena }\end{array}$ & E4 & $\begin{array}{l}\text { Licenciatura } \\
\text { em Educação } \\
\text { Física; } \\
\text { Bacharelado } \\
\text { em Letras/ } \\
\text { Libras. }\end{array}$ & $\begin{array}{l}\text { Especialização em: } \\
\text { Educação especial, } \\
\text { Libras - docência e } \\
\text { interpretação. } \\
\text { Mestrado em } \\
\text { Educação. }\end{array}$ & +10 anos & Maio/2013 \\
\hline P5 & $\begin{array}{l}\text { Guarani- } \\
\text { Kaiowá }\end{array}$ & $\begin{array}{l}\text { Curso } \\
\text { Teko } \\
\text { Arandu }\end{array}$ & Pedagogia & $\begin{array}{l}\text { Especialização em: } \\
\text { Educação especial; } \\
\text { Psicopedagogia. }\end{array}$ & Nenhuma & Nenhuma \\
\hline
\end{tabular}

Fonte: Dados de pesquisa. Elaboração dos autores.

Este quadro revela que apenas $50 \%$ dos professores do AEE são indígenas. Isso pode representar uma lacuna e um desafio no modo de formar os professores indígenas para a educação especial. O AEE nas escolas indígenas necessita de um trabalho dos professores da própria comunidade, capazes de entender como as famílias pensam e almejam a educação escolar de seus filhos com deficiências. Talvez este trabalho possa ocorrer na reelaboração do Projeto Político-Pedagógico, Regimento Escolar 
e nas assembleias/reuniões semestrais com os pais. A tradução cultural consiste na realização da hermenêutica diatópica, na qual "[...] uma necessidade, uma aspiração, uma prática numa dada cultura pode ser tornada compreensível e inteligível para outra cultura" (Santos 2009, p. 31).

As professoras P1, P2 e P4 são efetivas e remanejadas para o AEE porque estão lotadas em outra função da educação básica. Não houve, até o presente momento, um concurso específico para professor do AEE em Dourados. Isto dificulta uma política de valorização permanente desse profissional no município.

Quanto à formação inicial, observou-se que das 5 professoras entrevistadas, 2 possuem Pedagogia, 2 têm licenciatura em Educação Física (uma delas é formada como bacharel em Letras/Libras), e outra é formada em Normal Superior. Quanto à disciplina de educação especial, apenas a P3 disse que não cursou na graduação. Suas identidades docentes foram formadas por diferentes experiências na graduação.

Assim, a formação das professoras para o AEE nas escolas indígenas reflete a conjuntura nacional, na qual o processo de formação de educadores para o atendimento especializado não se efetua de maneira progressiva e continuada. Estudos de Queiroz Júnior (2010), Milanesi (2012) e Nozu (2013) relatam que a política de formação de professores para a educação especial era esporádica e limitada. Essa política começa a investir nessa modalidade a partir dos programas de formação ofertados pelo MEC (2007).

Esses pesquisadores discutem que a formação do docente para o AEE é generalista, diversificada e vaga porque tiveram qualificação para atuar no AEE por meio da formação em serviço. A P1 foi a única que fez a especialização em AEE ofertada pelo MEC, através do Programa Rede de Formação Continuada de professores na educação especial no âmbito do Sistema Universidade Aberta do Brasil (UAB). A P2 e a P4 fizeram especialização em Libras e um curso em educação especial pela Semed. A P3, além de possuir uma especialização em educação Inclusiva, também fez esse curso da Semed. Apenas a P4 possui uma pós-graduação strictu sensu.

A interface da educação especial com a educação escolar indígena torna-se ainda mais emblemática, como já mencionado, pois não há diretrizes específicas para a formação de professores indígenas nessa modalidade de ensino, como pode se ver no Parecer $n^{\circ}$. 13/2012 e na Res. $n^{\circ}$ 5/2012, há silêncio sobre a formação para o AEE e sobre essa interface.

Sob a perspectiva dos Estudos Culturais, pondera-se que os professores do AEE das escolas indígenas estão em situação de trânsito entre as fronteiras de duas modalidades (educação especial e educação indígena) e traduzi-las para a sua cultura, podem negociar os saberes e constituir identidades conforme suas vivências e pertencimentos.

Bauman (2005) compara a identidade com as peças de um quebra-cabeça 
incompleto. A construção da identidade é como uma bricolagem. Trata-se de uma tarefa que envolve toda uma vida e leva o ser humano a se libertar da "[...] inércia dos costumes tradicionais, das autoridades imutáveis, das rotinas preestabelecidas e das verdades inquestionáveis" (Bauman, 2005, p. 56).

Nesse sentido, as interlocutoras desta pesquisa tiveram a liberdade de construir as suas identidades nos espaços intersticiais de sua formação. Em razão disso, a política educacional precisa repensar como é possível implementar um programa de formação para professores indígenas capaz de atender as crianças indígenas com deficiência, principalmente, porque outras pesquisas evidenciaram limites na formação dos professores indígenas ou não que atuam em escolas indígenas.

No estudo de Costa de Sousa (2013), levantou-se que a formação inicial da maioria dos professores que atuam no AEE, nas escolas indígenas de Dourados, é a pedagogia. Na pesquisa de Lima (2013), os 4 professores indígenas que trabalham ou já trabalharam com crianças indígenas surdas incluídas em classe comum possuíam formação para o magistério e apenas 2 dispunham de formação específica para a educação indígena, pois têm Licenciatura Teko Arandu e Ara Verá (Magistério em Nível Médio). Esses professores trabalhavam com português/guarani nas séries iniciais. Dos 4 professores, apenas um deles possuía especialização na área da surdez, com $360 \mathrm{~h}$ de Libras. Outros 2 professores não tiveram nenhuma formação em Libras ou em educação de pessoas surdas. Enquanto o quarto teve uma formação aligeirada, com 40h de Libras, mas não suficientes para a comunicação nessa língua (Lima, 2013).

Em relação à inclusão da criança surda no espaço escolar, os professores demonstram dificuldades e lacunas no seu trabalho, principalmente, diante de uma formação que não potencializa suas práticas pedagógicas. Eles, porém, reconhecem a urgência da formação em Libras para o desenvolvimento dos educandos (Lima, 2013).

Segundo Silva Souza (2011, p. 113), "[...] a formação de professores indígenas para atuarem no campo da educação especial é uma questão nova e ainda pouco debatida pelos órgãos responsáveis pela educação indígena e pelas comunidades indígenas de abrangência". A formação profissional desses professores corresponde ao modelo não-indígena.

Dessa forma, percebeu-se, como Nóvoa ensina (1997, p. 24), que "[...] a formação de professores pode desempenhar um papel importante na configuração de uma 'nova' profissionalidade, estimulando a emergência de uma cultura profissional no seio do professorado e de uma cultura organizacional no seio das escolas". A formação de professores para o AEE nas escolas indígenas é imprescindível para garantir um atendimento educacional adequado às crianças indígenas com deficiência. Ela também é fundamental para incentivar a criação de uma cultura escolar pautada nos seguintes princípios: diferenciada, específica, multilíngue que contemple as necessidades específicas dos indígenas com deficiência. Isso só será 
possível acontecer quando houver uma tradução cultural capaz de construir uma formação acadêmica adequada aos professores indígenas.

Esse processo de tradução cultural conta com o "Ainda-Não", que deve ser a força que motive os responsáveis pela escolarização a pensar novos territórios e mapas para a educação escolar indígena das pessoas com deficiência. De acordo com Santos (2004, p. 795-796, grifos do autor), "Ainda-Não é a categoria mais complexa, porque exprime o que existe apenas como tendência, um movimento latente no processo de se manifestar. O Ainda-Não é o modo como o futuro se inscreve no presente e o dilata [...]".

\section{A formação continuada das professoras do AEE}

A formação de professores para o $\mathrm{AEE}$ do universo pesquisado acontece geralmente em serviço. Ela ocorre por meio de cursos de aperfeiçoamento e especialização. Como preleciona Jesus e Effgen (2012, p. 17), a formação continuada é uma "[...] possibilidade de pensar as demandas escolares e os processos de escolarização dos sujeitos que também são público-alvo da educação especial". Essa formação não pode ser somente para o crescimento de carreira docente, mas para que seus conhecimentos sejam revisados, autocriticados e aperfeiçoados (Tardif, 2012).

No contexto desta pesquisa, as professoras P1, P2 e P4 foram formadas como intérpretes por meio de aperfeiçoamento, sendo gerenciadas por instituições do ensino superior. A P1 atuava como professora intérprete itinerante para atender alunos surdos na E3. A P2 não dominava Libras, mas tinha interesse em aprofundar, porque fez o curso de Libras-Básico realizado na Universidade Federal de Mato Grosso do Sul (UEMS). A P4 possuía proficiência em Libras para o ensino dessa língua e para tradução/interpretação, como exige a lei nos arts. $7^{\circ}$ e $8^{\circ}$ (Brasil, 2005). A P5 frequentava o curso de Libras-Intermediário pela Semed e teve uma disciplina na graduação sobre Educação especial.

A política educacional dispõe, nos arts. $11, \S 3^{\circ}, 4^{\circ}$ que deve ser garantido o ensino da Libras nas escolas indígenas (Brasil, 2012b). Contudo, a Libras corresponde a uma língua convencionada por surdos não-indígenas. Os surdos indígenas de Dourados possuem sinais emergentes que não se constituem ainda numa língua. Por isso, as escolas indígenas precisam repensar o ensino da língua de sinais para esses alunos.

$\mathrm{Na}$ opinião das professoras pesquisadas, a Libras foi imposta nas escolas indígenas, apesar dela permitir a comunicação e a interação entre os professores e os alunos indígenas surdos. Para a descolonização ${ }^{1}$ da Libras nessas escolas, torna-

\footnotetext{
${ }^{1}$ Walsh (2009, p. 24) fala de uma orientação de-colonial para "visibilizar, enfrentar e transformar as estruturas e instituições que diferencialmente posicionam grupos, práticas e pensamentos dentro de uma ordem e lógica que, ao mesmo tempo e ainda, é racial, moderno-ocidental e colonial".
} 
se necessário promover debates entre a comunidade indígena, os linguistas que estudam as línguas guarani-kaiowá, profissionais de Libras e os professores de surdos.

Assim, cabe à escola decidir como será trabalhada a língua materna dos indígenas surdos. A escola e a família precisam de informações sobre as necessidades dessas pessoas. Também necessitam desenvolver estratégias para que o aprendizado delas se efetive, discutindo, sobretudo, o papel do professor intérprete e a posição do indígena surdo na comunidade.

Além disso, todas as professoras fizeram cursos na grande área de educação especial. Somente a P1 fez a especialização ofertada pelo MEC, como já foi comentado, o que representa uma formação generalista, criticada por Bruno (2007), Queiroz Júnior (2010), Baptista (2013) e outros, pois não atende as necessidades específicas da população com deficiência.

A partir de 2013, foi definida a formação continuada pelos próprios professores do AEE do município. No entanto, as professoras advertiram que esses encontros não dialogam com as diretrizes de uma educação escolar indígena. Faltam cursos que abordem as reais necessidades das suas escolas. Conforme pode ser observado na fala das professoras, as temáticas propostas partem das demandas das escolas municipais urbanas:

Eu penso que nós deveríamos estar estudando como estamos fazendo atualmente com a Secretaria de Educação, com a equipe, sempre lendo sobre as várias deficiências, discutindo as teorias e teóricos e tal; mas também é muito importante a prática e o específico da escola indígena, assim como estamos estudando nesta formação com vocês [referindo-se a esta pesquisa]. (P3)

Concordo com a P3, do jeito que a gente está fazendo agora é bacana, troca de experiências [...]. Então eu acho que estamos no caminho certo, mas na parte da educação escolar indígena, falar da realidade de aldeia, eu acho que é, não, é diferente! (P1)

[...] dentro das escolas indígenas, às vezes a gente encontra realidade totalmente diferente, que é aqui é entre nós mesmo, trocamos, mas essa forma de encontro é lá na cidade e não tem um encontro específico com a escola indígena. (P2)

Segundo as professoras, a interação entre elas nos cursos da Semed era positiva, porque estavam aprendendo juntas e colaborando com a sua própria formação, mas ficava a desejar o aspecto da qualidade da formação, porque elas possuem o perfil de formação e o nível de conhecimento de forma diferenciada. Em razão disso, 
elas afirmaram que os professores do AEE das escolas indígenas precisavam ter discussões frequentes em conjunto.

De acordo com Nóvoa (1997, p. 26), a troca de experiência e a partilha de saberes entre os professores "[...] consolidam espaços de formação mútua, nos quais cada professor é chamado a desempenhar, simultaneamente, o papel de formador e de formado". O diálogo entre os professores é "[...] fundamental para consolidar saberes emergentes da prática profissional" (Nóvoa, 1997, p. 26). Por isso, as professoras acreditavam que a formação continuada, proposta por esta pesquisa, poderá colaborar com a discussão e a criação de estratégias para atender as crianças indígenas com deficiência.

Em síntese, as próprias professoras das salas de recursos reconheciam a importância de uma formação continuada, mas reivindicam uma abordagem para o contexto do AEE em escolas indígenas. A formação continuada do professor precisa se pautar nas suas demandas e nos projetos políticos-pedagógicos das escolas indígenas. As formações acadêmicas das interlocutoras desta pesquisa, tanto no âmbito inicial quanto continuado, não correspondem aos princípios e projetos das escolas indígenas. A formação dos docentes requer aproximação das expectativas sóciocomunitárias dos guarani-kaiowá, de forma que contemplem a participação das famílias, dos alunos, dos professores e da comunidade.

No caso desta pesquisa, é preciso pensar numa formação dos professores orientada à diversidade. Para Jesus e Effgen (2012, p. 21), num contexto da diversidade, a formação docente requer uma rede de encontros: "Encontros de saberes, fazeres, reflexões, metodologias, estratégias de ensino, recursos, perspectivas avaliativas, pois, dessa forma, estaremos constituindo sujeitos coletivos". Todavia, percebese como Jesus e Effgen (2012, p. 21) "[...] que a formação docente qualificada pode muito, mas não pode tudo. Há que se pensar em outros aspectos macro que configuram os sistemas de ensino e as condições de trabalho docente".

Por isso, compreende-se que a realização da formação continuada para os professores do AEE nas escolas indígenas deve ser repensada. Essa formação precisa elaborar diretrizes capazes de articular a educação inclusiva e intercultural. Baseando-se nos Estudos Culturais, analisa-se que é preciso respeitar as lógicas e as (re)significações dos processos de hibridação cultural e dos saberes indígenas. A formação de professores do AEE para as escolas indígenas constitui-se em espaços fronteiriços (culturais e sociais) que interpelam o contexto educacional para sair em busca dos entre-lugares. Essa formação implica traduções inesgotáveis de significado para as escolas indígenas. Ela também contribui com o diálogo intercultural entre as políticas educacionais e a gestão educacional. 


\section{A percepção das professoras do AEE sobre a experiência e o exercício da docência}

Observou-se que o tempo de serviço das professoras na área da Educação especial é diverso. A P1 trabalhava há quase 3 anos como intérprete e 3 anos na sala de recursos. A P2 atuava há quase 5 anos como intérprete e 2 anos como professora do AEE. A P3 estava no $3^{\circ}$ ano de trabalho consecutivo no AEE. Ela possuía experiência anterior em Apaes. A P4 trabalhava há 7 anos como intérprete. Ela começou a trabalhar no AEE em maio de 2013.

O ponto fulcral das experiências dessas professoras foi analisar as suas percepções quanto à formação inicial/continuada, a sua profissão e atuação no AEE. Quanto à formação inicial, a P2 informou que fez um ótimo curso de Magistério (Nível Médio), entre 1994 a 1999. Esse curso oportunizou seu contato com a Educação especial quando realizou estágio na Apae. Entretanto, ela percebeu a necessidade de participar de outros cursos para melhorar o seu atendimento na sala de recursos. Para a P3, a sua formação inicial (Normal Superior) e a sua experiência no trabalho na Apae em Minas Gerais contribuíram com o atendimento das crianças indígenas com deficiência, principalmente, na parte da alfabetização. Porém, ela esclareceu que tinha dificuldade com criança surda e paralisia cerebral. Em razão de sua formação em Pedagogia, a P1 disse que tinha facilidade em atender as crianças que estavam nos primeiros anos do ensino fundamental, mas tem dificuldade com as crianças dos últimos anos dessa etapa, porque esse trabalho requer o domínio de conhecimentos específicos (geografia, história e ciências).

Diante de tudo isso, percebe-se que, como preleciona Tardif (2012), os cursos de formação para o magistério são globalmente idealizados segundo um modelo aplicacionista do conhecimento: os alunos passam alguns anos na universidade, aprendem conhecimentos proporcionais e ao se formarem vão para o mercado de trabalho. Neste local, sentem-se sozinhos e percebem que os conhecimentos adquiridos não se aplicam a sua ação cotidiana.

Até mesmo o currículo da graduação interfere na competência do professor do AEE (Cortelazzo, 2012). A formação inicial do professor precisa contemplar conhecimentos, habilidades e atitudes que lhes oportunizem um trabalho diferenciado e inclusivo com as crianças em situação de deficiência. Essa formação precisa contemplar as modalidades de educação especial e de educação indígena, e outras, para que o professor seja qualificado para atuar nesses âmbitos. Geralmente, os cursos têm apenas certificados, os professores com conhecimentos básicos, não potencializando áreas específicas. Quase sempre, os próprios docentes precisam aprimorar os seus conhecimentos específicos em futuras especializações ou cursos de aperfeiçoamento.

Nóvoa (1997) ensina que a formação não se constrói por acumulação de cursos, 
mas por meio do trabalho de reflexividade crítica sobre as práticas e reconstrução permanente de uma identidade pessoal ${ }^{2}$. Assim, a formação docente e as experiências do trabalho corroboram na percepção da sua profissão. Neste ponto, as interlocutoras desta pesquisa a compreendiam de forma diferenciada. Para a $\mathrm{P} 2$, um dos pontos positivos em ser professora do AEE das escolas indígenas é o respeito e a valorização por parte dos pais:

Eu me sinto realizada como professora, assim dentro da comunidade, lá fora não, mas dentro da comunidade indígena o professor é bem visto, eu até lembro-me de uma fala da professora P3, um dia que ela falou assim: o professor dentro da comunidade é uma autoridade [...].

A P1 informou que o tipo de qualificação do professor não implica numa hierarquia de funções a serem desempenhadas nas escolas indígenas. Apesar de ela ter uma específica formação para o AEE e pertencer à etnia terena, o seu trabalho deve corresponder aos anseios da comunidade guarani-kaiowá, ou seja, prestar um trabalho de diálogo e de interculturalidade.

As interlocutoras desta pesquisa sentiam, de forma diferenciada, a função de serem professoras regentes e de serem professoras do AEE. Todas concordaram que estavam satisfeitas com a escolha profissional de serem docentes. No entanto, na identificação com exercício da função de docência do AEE revelaram descontentamentos e insegurança, como pode ser lido no relato abaixo:

Não era meu objetivo ser professora do AEE. Eu queria trabalhar como intérprete, trabalhei e foi uma boa experiência. O AEE surgiu quando a Elza me ofereceu uma formação. Nem sabia o que era o AEE [...]. Aí eu aceitei [...]. (P1)

Eu trabalhei por um tempo como professora, com aluno especial [...] e; aprendi Libras para ter comunicação com os alunos indígenas surdos [...]. Não me sinto frustrada na sala de recursos, tem hora, assim, eu me sinto angustiada, porque sei das minhas limitações para algumas coisas [...]. Então, estou me sentindo não totalmente realizada, acho que falta muito, mas eu pretendo contribuir e muito ainda para melhorar a educação especial indígena. (P2)

Quando surgiu essa oportunidade a Elza me chamou para trabalhar, para começar o AEE ali na escola, para mim foi tranquilo, mas assim, quanto às crianças, eu não tenho problema nenhum. A minha dificuldade maior, está em relação aos professores da sala comum, até com a coordenação, em relação ao trabalho da sala. Então, muitas vezes, nesses três anos, eu tenho sentido vontade de voltar para sala comum [...]. Ser

2 Segundo Franco e Gentil (2007, p. 4), a identidade "[...] apresenta traços afetivos, relaciona-se a valores, engendra-se a partir de possibilidades, de histórias coletivas, é fruto da relação coletiva com um sistema maior, mas, sobretudo, é fonte de referência e compreensão". 
professora, eu quero continuar até aposentar e depois continuar trabalhando só com essa área mesmo, mas quanto a continuar a ser professora do $\mathrm{AEE}$, vai depender desse próprio serviço. (P3)

[...] eu me identifico mais na educação de surdos, tenho minhas formações, posso atuar como tradutora/intérprete, porém, não posso atuar por ser concursada numa outra área, então deveria ser apenas convocada, contratada. [...]. (P4)

A partir do relato dessas professoras, destaca-se a iniciação dessas docentes no exercício do AEE e a sua preparação para o mesmo, bem como a identificação delas com trabalho realizado.

Cabe ressaltar, que a P1 foi a primeira professora do AEE das escolas indígenas. Elas foram preparadas diferentemente umas das outras. A P1 fez o curso do governo federal, a P2 e a P3 fizeram uma formação continuada gerenciada pelo Núcleo de Educação Especial. No segundo ponto, compreende-se a identificação como a "[...] criação de laços mais duradouros de vivência partilhada, o que por sua vez leva à construção coletiva de significados" (Franco; Gentil, 2007, p. 3). A P1 e a P4 disseram ter interesse em mudar de função. Pretendiam voltar ao trabalho de intérpretes, pois pensavam que possuíam uma adequada competência para atuar nesse serviço. A P1 expôs seu objetivo de vida nestes termos: "meu sonho é voltar a interpretar". Já a P2 e a P3 tinham o objetivo de dar continuidade aos estudos no AEE. Elas revelaram insatisfação com o trabalho do $A E E$, principalmente pela necessidade de novos conhecimentos, condições materiais e recursos humanos para trabalharem.

Esses sentimentos de identificação com o $A E E$ correspondem também às dificuldades advindas da realidade escolar indígena, sobretudo por não haver uma formação que contemple conhecimentos consistentes sobre as diferentes deficiências. $O$ fato de as professoras não se sentirem realizadas no AEE parte das circunstâncias funcionais e do despreparo para atuar com crianças com diferentes condições em contexto indígena.

A formação realizada por essas professoras não consegue responder às necessidades de todas as crianças na proposta generalista do AEE. Elas destacaram a preponderância da formação na área da surdez e a falta de conhecimento em relação às necessidades e ao trabalho de alunos com deficiência intelectual e múltipla. Também revelaram uma indefinição ou desconhecimento da sua função para outros professores, colegas e coordenação da escola. Para elas, a função do professor estava politicamente bem definida. Porém, falta uma melhor compreensão por parte desses profissionais da educação no que tange ao trabalho do professor do AEE.

Dessa forma, é possível afirmar que novas identidades docentes estão sendo 
moldadas, apropriadas, transformadas nas escolas indígenas. As identidades são deslocadas, descentradas e fragmentadas, como fala Hall (2006). Elas também são negociáveis e revogáveis (Bauman, 2005).

Neste sentido, as identidades das professoras do AEE para escolas indígenas não são fixas e estáveis. Elas são construídas pelos docentes, na tradução cultural de suas experiências, no trânsito entre as fronteiras sociais, linguísticas e culturais. Para Bhabha (1998), o homem vive nos interstícios sociais (a sobreposição e o deslocamento de domínios da diferença), através dos quais as relações entre os indivíduos e interesses diversos são negociadas. Isso se torna possível quando os professores transitam pelos saberes da cultura Guarani-Kaiowá e negociam com os saberes dos não-indígenas, haja vista as condições socioculturais que Bhabha (1998, p. 301, grifos do autor) reflete:

Oque está em questãoéa natureza performativa das identidades diferenciais: a regulação e a negociação daqueles espaços que estão continuamente, contingencialmente, se abrindo, retraçando as fronteiras, expondo os limites de qualquer alegação de um signo singular ou autônomo de diferença - seja ele classe, gênero ou raça. Tais atribuições de diferenças sociais - onde a diferença não é nem o Um nem o Outro, mas algo além, intervalar - encontram sua agência em uma forma de um 'futuro' em que o passado não é originário, em que o presente não é simplesmente transitório. Trata-se, se me permitem levar adiante o argumento, de um futuro intersticial, que emerge no entremeio entre as exigências do passado e as necessidades do presente.

\section{Considerações Finais}

A formação de professores indígenas para o AEE encontra-se entre-lugares e no contexto de novas identidades a serem negociadas e construídas. A presente pesquisa evidencia que uma política para esse tipo de formação é prioritária para a permanência das crianças indígenas com deficiência nas escolas indígenas com qualidade sociocultural e que respeite as características e diretrizes da educação escolar indígena.

A oferta do AEE nas escolas indígenas configura-se por contradições, tensões e desafios, entre os quais: formação de professores que valorize a língua, a tradição e culturas das diferentes etnias; fortaleça a formação com o domínio de saberes sobre as necessidades específicas e educacionais dos educandos indígenas com deficiência e que possibilite a efetive a articulação entre diferentes campos de conhecimento educação especial e educação escolar indígena numa proposta intercultural. 


\section{Referências}

BAPTISTA, Cláudio Roberto. Ação Pedagógica e Educação especial: para além do AEE. In: JESUS, Denise Meyrelles de; BAPTISTA, Cláudio Roberto; CAIADO, Kátia Regina Moreno (Org.). Prática Pedagógica na Educação especial: multiplicidade no atendimento educacional. Araraquara, SP: Junqueira \& Marin, 2013. p. 43-62.

BAUMAN, Zygmunt. Identidade: entrevista a Benedetto Vecchi. Rio de Janeiro: Jorge Zahar, 2005.

BHABHA, Homi K. O local da cultura. Belo Horizonte: UFMG, 1998.

BRASIL. Lei 13.005, de 25 de junho de 2014. Aprova o Plano Nacional de Educação - PNE e dá outras providências. Brasília, DF: Senado Federal, 2014.

Parecer CNE/CEB n. 13, de 10 de maio de 2012. Assunto: Diretrizes Curriculares Nacionais para a Educação Escolar Indígena. Brasília, DF: MEC/CNE/ CEB, 2012a.

. Resolução CNE/CEB n. 5, de 22 de junho 2012. Define Diretrizes Curriculares

Nacionais para a Educação Escolar Indígena na Educação Básica. Brasília, DF: MEC/CNE/CEB, 2012b.

. Política Nacional de Educação especial na perspectiva da educação inclusiva. Brasília, DF: MEC/SEESP, 2008.

. Decreto n. 5.626, de 22 de dezembro de 2005. Regulamenta a Lei no 10.436, de 24 de abril de 2002, que dispõe sobre a Língua Brasileira de Sinais - Libras, e o art. 18 da Lei no 10.098, de 19 de dezembro de 2000. Brasília, DF: Senado Federal, 2005.

. Resolução n. 1, de 15 de maio de 2006. Institui Diretrizes Curriculares Nacionais para o Curso de Graduação em Pedagogia, licenciatura. Brasília, DF: MEC/CNE/CP, 2006.

. Referenciais para a formação de professores indígenas (RFPI). Brasília, DF: MEC, 2002. 1998.

. Referencial Curricular Nacional para as Escolas Indígenas. Brasília, DF: MEC, 
BRUNO, Marilda Moraes Garcia. Educação Inclusiva: Componente da Formação de Educadores. Revista Benjamin Constant, Rio de Janeiro, ano 13, n. 38, dez. 2007. Disponível em: <http://saci.org.br/index.php?modulo=akemi\&paramet ro=21054 $>$. Acesso em: 07 fev. 2012.

CORTELAZZO, Iolanda Bueno de Camargo. Formação de professores para uma educação inclusiva mediada pelas tecnologias. In: GIROTO, Claudia Regina Mosco; POKER, Rosimar Bortoloni; OMOTE, Sadao (Org.). As tecnologias nas práticas pedagógicas inclusivas. Marília/SP: Cultura Acadêmica, 2012. p. 93-120.

COSTA DE SOUSA, Maria do Carmo da Encarnação. A Organização do Atendimento Educacional Especializado nas Aldeias Indígenas de Dourados/MS: um estudo sobre as salas de recursos multifuncionais para área da surdez. 2013 (111 f.). Dissertação (Mestrado em Educação) - Programa de Pós-Graduação em Educação, Universidade Federal Grande de Dourados, 2013.

ESCOSTEGUY, Ana Carolina Damboriarena. Cartografias dos estudos culturais Uma versão latino-americana. Belo Horizonte: Autêntica, 2010.

FRANCO, Maria Estela Dal Pai; GENTIL, Heloisa Salles. Identidade do Professor de Ensino Superior: questões no entrecruzar de caminhos. In: FRANCO, FRANCO, Maria Estela Dal Pai; KRAHE, Elizabeth Diefenthaeler (Org.). Pedagogia Universitária e Áreas de Conhecimento. Porto Alegre: EdiPucRS, 2007. p. 39-58.

GARCÍA CANCLINI, Nestor. Culturas Híbridas: Estratégias para entrar e sair da modernidade. 4. ed. São Paulo: USP, 2008.

GEERTZ, Clifford. Nova luz sobre a antropologia. Rio de Janeiro: Jorge Zahar, 2001. A interpretação das culturas. 1. ed. 13 ${ }^{\text {a }}$ reimp. Rio de Janeiro: LTC, 2008.

HALL, Stuart. Da Diáspora: identidade e mediações. Belo Horizonte: UFMG, 2003. A Identidade Cultural na Pós-modernidade. 11. ed. Rio de Janeiro: DP\&A, 2006.

IBIAPINA, Ivana Maria Lopes de Melo. Pesquisa Colaborativa: Investigação, Formação e Produção de conhecimentos. Brasília: Liber, 2008. (Série Pesquisa).

JESUS, Denise Meyrelles de; EFFGEN, Ariadna Pereira Siqueira. Formação docente e práticas pedagógicas: conexões, possibilidades e tensões. In: MIRANDA, Theresinha Guimarães; GALVÃO FILHO, Teófilo Alves. (Org.). O professor e a educação inclusiva - formação, práticas e lugares. Salvador: EDUFBA. 2012, p. 1724. 
LACLAU, Ernesto. Emancipação e diferença. Rio de Janeiro: EdUERJ, 2011.

LIMA, Juliana Maria da Silva. Criança Indígena Surda na Cultura Guarani-Kaiowá: um estudo sobre as formas de comunicação e inclusão na família e na escola. 2013 (123 f.). Dissertação (Mestrado em Educação) - Programa de Pós-Graduação em Educação, Universidade Federal da Grande Dourados, 2013.

MILANESI, Josiane Beltrame. Organização e Funcionamento das Salas de Recursos Multifuncionais em um Município Paulista. 2012 (183 f.). Dissertação (Mestrado em Educação especial) - Programa de Pós-Graduação em Educação especial, Universidade Federal de São Carlos, 2012.

NÓVOA, António. Formação de professores e profissão docente. In: NÓVOA, António (Coord.). Os Professores e a sua formação. 3. ed. Lisboa, Portugal: Dom Quixote, 1997. p. 15-34.

NOZU, Washington César Shoiti. Política e Gestão do Atendimento Educacional Especializado nas Salas de Recursos Multifuncionais de Paranaíba/MS: uma análise das práticas discursivas e não discursivas. 2013 (241 f.). Dissertação (Mestrado em Educação) - Programa de Pós-Graduação em Educação, Universidade Federal da Grande Dourados, 2013.

QUEIROZ JÚNIOR, Edison de. Formação continuada de professores para o Atendimento educacional especializado: desafios e perspectivas. 2010 (117 f.). Dissertação (Mestrado em Educação) - Programa de Pós-Graduação em Educação, Universidade de São Paulo, 2010.

SANTOS, Boaventura de Sousa. A Crítica da Razão Indolente: contra o desperdício da experiência. 7. ed. São Paulo: Cortez, 2009.

. Para uma sociologia das ausências e uma sociologia das emergências. In: .(Org.). Conhecimento Prudente para uma vida decente: um discurso sobre as ciências revisitado. São Paulo: Cortez, 2004. p. 777-821.

SILVA SOUZA, Vânia Pereira. da. Crianças indígenas Kaiowá e Guarani: um estudo sobre as representações sociais da deficiência e o acesso às políticas de saúde e educação em aldeias da Região da Grande Dourados. 2011 (105 f.). Dissertação (Mestrado em Educação) - Programa de Pós-Graduação em Educação, Universidade Federal Grande de Dourados, 2011.

TARDIF, Maurice. Saberes docentes e formação profissional. Petrópolis: Vozes, 2012. 
WALSH, Catherine. Interculturalidade, Crítica e Pedagogia Decolonial: in-surgir, re-existir e re-viver. In: CANDAU, Vera Maria (Org.). Educação intercultural na América Latina: entre concepções, tensões e propostas. Rio de Janeiro: 7 Letras, 2009. p. 12-42.

Recebido em julho de 2015

Aprovado em novembro de 2015

João Henrique da Silva é doutorando em Educação Especial pela Universidade Federal de São Carlos (UFSCar). E-mail: jhsilva1@yahoo.com.br

Marilda Moraes Garcia Bruno é doutora em Ensino da Educação Brasileira pela Universidade Estadual Paulista Júlio de Mesquita Filho (Unesp) e professora da Universidade Federal da Grande Dourados (UFGD). E-mail: marildabruno@ufgd.edu.br 